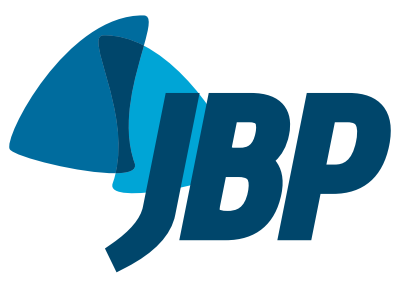

\title{
Ultrasound-guided intrapleural positioning of pleural catheters: influence on immediate lung expansion and pleurodesis in patients with recurrent malignant pleural effusion
}

\author{
Pedro Henrique Xavier Nabuco de Araujo', Ricardo Mingarini Terra', \\ Thiago da Silva Santos ${ }^{1}$, Rodrigo Caruso Chate ${ }^{2}$, Antonio Fernando Lins de Paiva ${ }^{2}$, \\ Paulo Manuel Pêgo-Fernandes ${ }^{1}$
}

1. Divisão de Cirurgia Torácica, Hospital das Clínicas, Faculdade de Medicina, Universidade de São Paulo, São Paulo (SP) Brasil.

2. Divisão de Radiologia, Hospital das Clínicas, Faculdade de Medicina, Universidade de São Paulo, São Paulo (SP) Brasil.

Submitted: 10 August 2016 Accepted: 5 January 2017

Study carried out in the Divisão de Cirurgia Torácica, Hospital das Clínicas, Faculdade de Medicina, Universidade de São Paulo, São Paulo (SP) Brasil.

\begin{abstract}
Objective: To evaluate the role of intrapleural positioning of a pleural catheter in early lung expansion and pleurodesis success in patients with recurrent malignant pleural effusion (RMPE). Methods: This was a retrospective study nested into a larger prospective cohort study including patients with RMPE recruited from a tertiary university teaching hospital between June of 2009 and September of 2014. The patients underwent pleural catheter insertion followed by bedside pleurodesis. Chest CT scans were performed twice: immediately before pleurodesis (iCT) and 30 days after pleurodesis (CT30). Catheter positioning was categorized based on $\mathrm{iCT}$ scans as posterolateral, anterior, fissural, and subpulmonary. We used the pleural volume on ICT scans to estimate early lung expansion and the difference between the pleural volumes on CT30 and ICT scans to evaluate radiological success of pleurodesis. Clinical pleurodesis success was defined as no need for any other pleural procedure. Results: Of the 131 eligible patients from the original study, 85 were included in this nested study (64 women; mean age: 60.74 years). Catheter tip positioning was subpulmonary in 35 patients (41\%), anterior in $23(27 \%)$, posterolateral in $17(20 \%)$, and fissural in $10(12 \%)$. No significant differences were found among the groups regarding early lung expansion (median residual pleural cavity $=377$ $\mathrm{mL}$; interquartile range: $171-722 \mathrm{~mL} ; \mathrm{p}=0.645$ ), radiological success of pleurodesis (median volume $=33 \mathrm{~mL}$; interquartile range: -225 to $257 \mathrm{~mL} ; \mathrm{p}=0.923$ ), and clinical success of pleurodesis $(85.8 \% ; p=0.676)$. Conclusions: Our results suggest that the position of the tip of the pleural catheter influences neither early lung expansion nor bedside pleurodesis success in patients with RMPE.
\end{abstract}

Keywords: Pleurodesis; Pleural effusion, malignant; Tomography; Catheters.

\section{INTRODUCTION}

Chest tubes are used to remove liquid or air from the pleural space. Quite often, patients with recurrent malignant pleural effusion (RMPE) undergo chest tube insertion not only to allow lung reexpansion but also as an access route for bedside pleurodesis. Therefore, in the RMPE scenario, the purpose of using a chest tube is to promote proper emptying of pleural fluid and to allow adequate contact between pleural surfaces, an important fact for successful pleurodesis. In addition, the chest tube must allow easy distribution of the sclerosing agent over the pleural surface.

Large-bore tubes ( $\geq 24 \mathrm{Fr}$ ) have been widely used as an access route for bedside pleurodesis. ${ }^{(2)}$ However, pain is an issue both during tube insertion and during the time the tube is in place. ${ }^{(3)}$ Smaller chest tubes $(\leq 14 \mathrm{Fr}$ ) cause less pain, are easier to insert, and appear to reduce the risk of complications. ${ }^{(4)}$ Moreover, three randomized trials concluded that large-bore and small-bore tubes have equivalent efficacy in the palliation of RMPE. ${ }^{(5-7)}$
Because of the lack of evidence, positioning a chest tube is considered an issue by many. Manuals, guidelines, and review articles have suggested that the tube should lie posteriorly in the pleural cavity and directed to its apex; this statement makes sense anatomically speaking. ${ }^{(4,8,9)}$ Although it is easier to insert a small-bore chest tube or a pleural catheter, it is not so easy to locate its tip inside the pleural cavity. There is little evidence in the literature addressing this issue. Therefore, the objective of the present study was to evaluate the role of intrapleural positioning of a pleural catheter in early lung expansion and pleurodesis success in patients with RMPE.

\section{METHODS}

This was a retrospective study nested into a larger prospective cohort study whose aim was to evaluate the role of elastance in the success of pleurodesis in patients with RMPE (ClinicalTrials.gov Identifier: NCT01819363). All variables and outcomes were defined beforehand and were prospectively collected. The main study has been

Correspondence to:

Pedro Henrique Xavier Nabuco de Araujo. Divisão de Cirurgia Torácica, Avenida Dr. Enéas de Carvalho Aguiar, 44, CEP 05403-000, São Paulo, SP, Brasil. Fax: 5511 2661-5248. Email: phnabuco@icloud.com

Financial support: This study received financial support from the Fundação de Amparo à Pesquisa do Estado de São Paulo (FAPESP, São Paulo Research Foundation, Grant no. 2011/50838-5) 
completed, but the manuscript had yet to be sent for publication when the present one was submitted. All participating patients gave written informed consent, and the study was approved by the local research ethics committee (CAPPesq HCFMUSP-0654/11).

Patients were recruited between June of 2009 and September of 2013 at the University of São Paulo Medical School Hospital das Clínicas, a tertiary university teaching hospital located in the city of São Paulo, Brazil. The inclusion criteria were symptomatic RMPE (highly suspected or confirmed either by cytology or pleural biopsy), complete or partial lung expansion ( $\geq 70 \%$ ) after pleural drainage, and a Karnofsky Performance Status index $>30$. Highly suspected RMPE was considered when exudates from patients with confirmed metastatic cancer presented with lymphocytic predominance and low adenosine deaminase values. The exclusion criteria were age $<18$ years, previous pleural procedures, hemorrhagic diathesis, current infection, massive skin infiltration, and inability to understand quality-of-life questionnaires.

After being included, the participating patients were positioned in orthostatic position, and chest ultrasonography was performed by the attending physician (a board-certified thoracic surgeon) in order to select the best site for catheter placement. The preferred site was the most inferior position that was closest to the mid-axillary line; nevertheless, the placement varied considerably depending on ultrasound findings. After local anesthesia (lidocaine 2\%), pleural drainage was carried out with a 14-Fr pigtail catheter (C-UPTP-1400-WAYNE; Cook Medical, Bloomington, IN, USA) using the trocar technique. Whenever possible, we tried to push the tip of the catheter cranially and posteriorly.

Two days after pleural drainage, the patients were evaluated for lung expansion by means of a chest X-ray. The patients who presented with lung expansion $\geq$ $70 \%$ of the affected hemithorax (as adjudicated by two different raters) were considered eligible for pleurodesis; the remaining patients were excluded from the study. Prior to pleurodesis, the elected participants underwent an initial CT (iCT) of the chest. Then, pleurodesis was carried out using $30 \mathrm{~mL}$ of $0.5 \%$ silver nitrate solution or $3.6 \mathrm{~g}$ of talc in $60 \mathrm{~mL}$ of saline solution instilled through the catheter. The pleural catheter was removed 3-5 days after pleurodesis if the volume drained in 24 h was smaller than $200 \mathrm{~mL}$. All patients were followed closely at our outpatient clinic, with particular attention to adverse events and recurrences. On the 30th day after pleurodesis, the participants underwent another CT of the chest (CT30).

\section{Outcome measure}

The independent variable in the present study was the position of the intrapleural catheter, which was categorized as posterolateral, anterior, fissural, or subpulmonary positioning according to the location of the fenestrated portion of the catheter (tip of the pigtail catheter). Examples of each category are depicted in Figure 1. Two independent raters (board-certified thoracic surgeons), blinded to the outcome of the patients, analyzed the images and classified the patients into the abovementioned categories. When there was a disagreement between the raters, a third researcher evaluated the CT images and solved the impasse.

The dependent variables were early lung expansion and pleurodesis success. Both were evaluated according to residual pleural fluid or residual pleural cavity volumes as measured by $\mathrm{CT}$ of the chest. A radiologist specializing in thoracic radiology calculated the pleural volumes. The analyses were made with the software Aquarius Intuition Viewer ${ }^{\circledR}$ (TeraRecon, Foster City, CA, USA) using the segmentation analysis and tracking tool, which is suitable for the analysis and characterization of masses and segmented structures on CT scans; the area of interest is selected, and the program calculates its volume. Even after this initial calculation, it is possible for the radiologist to make any necessary corrections with the addition of targeted areas that were not included in the first assessment. We calculated the volumes in $\mathrm{mL}$. Early lung expansion was determined with the calculation of the pleural volume at iCT. Pleurodesis success was confirmed by the difference between the measurements of pleural volumes at CT30 and those at iCT. Pleurodesis success was also evaluated along the follow-up period as a binary variable (success or failure). Pleurodesis failure was defined as the need for any new procedure involving the pleura during the follow-up period. New procedures were indicated by the medical team of the pleural disease group when the patient presented recurrence of symptoms (dyspnea or chest pain) associated with radiological evidence of RMPE reaccumulation on chest $\mathrm{X}$-ray or $\mathrm{CT}$. We classified the adverse events according to the Common Terminology Criteria for Adverse Events version 4.0(10) as major events (score $\geq 3$ ) or minor events (score $\leq 2$ ).

\section{Statistical analysis}

Descriptive statistical analysis was used to summarize the characteristics of the patients studied, the success rates of pleurodesis, the residual pleural volume right after pleural drainage, and the reaccumulation of pleural effusion after pleurodesis. Numerical variables were tested for their distribution with the use of the Shapiro-Wilk and kurtosis tests. The pleurodesis success rates were compared among the groups, and the chi-square test was used to calculate the level of significance. The initial pleural volumes were compared among the groups using the Kruskal-Wallis test, as was the difference between final and initial pleural volumes. All analyses were carried out with a level of significance set at $p<0.05$.

\section{RESULTS}

During the study period, 131 patients were treated at our outpatient clinic and considered eligible for the original prospective study. Among these, 46 patients were excluded from the analysis: 25 due to death 


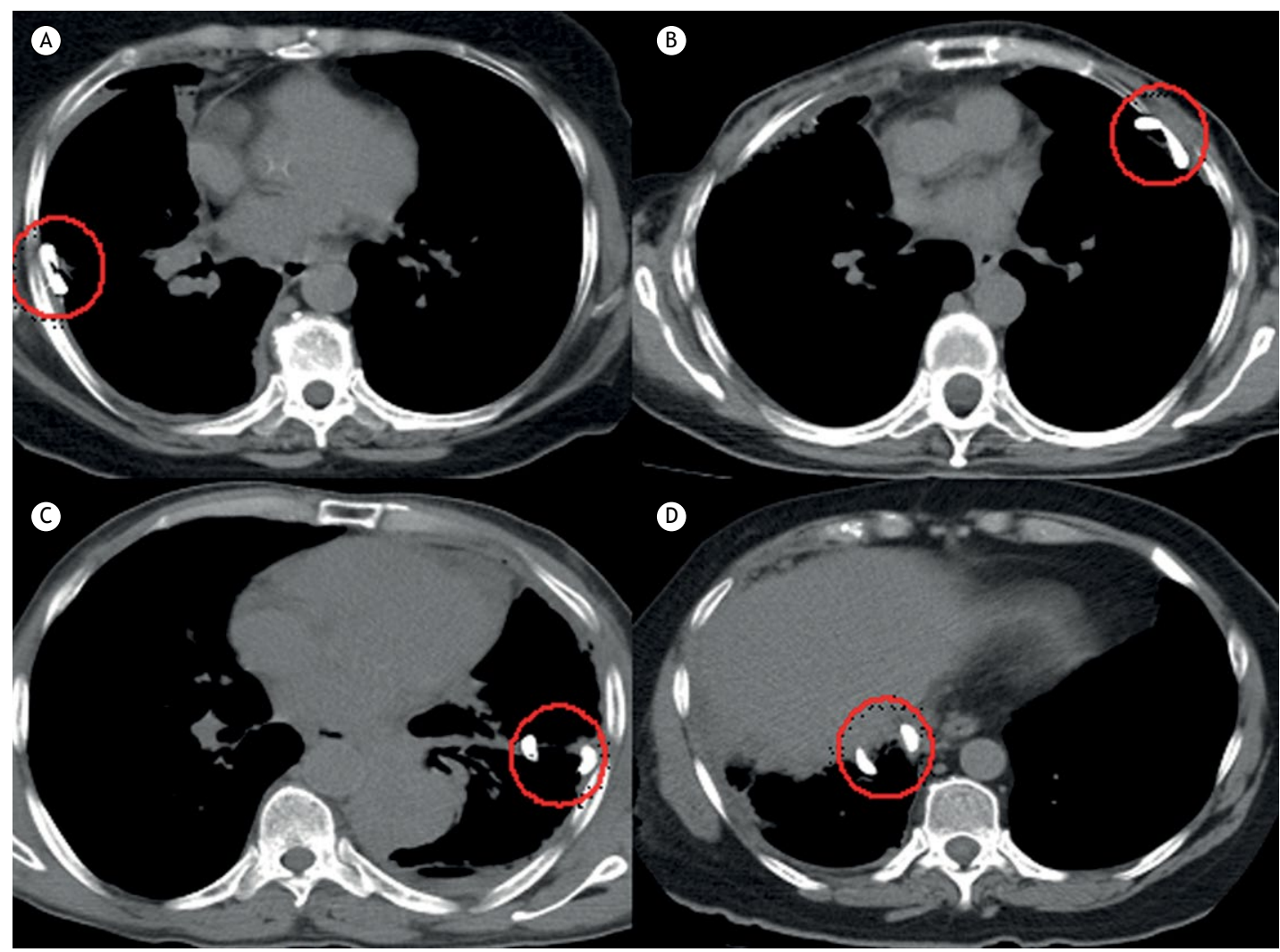

Figure 1. Positioning of the pleural catheter on CT scans. A: posterolateral; B: anterior; C: fissural; and D: subpulmonary.

(none related to the procedures) prior to 30 days after the procedures (i.e., no CT30 results), 15 due to lung expansion $<70 \%$, and 6 lost to follow-up. Therefore, 85 patients fulfilled the inclusion criteria and participated in the original study and in the present nested study. There was a predominance of women ( 64 vs. 21 men). The mean age was 60.74 years. The median Karnofsky Performance Status index was 70. Breasts and lungs were the most common primary sites of neoplasia (44 and 20, respectively). The characteristics of the patients studied are presented in Table 1.

Bedside pleurodesis was associated with significant morbidity in our series. Adverse events of any kind were identified in 13 patients (15.2\%), and some patients had more than one event, as well as major and minor complications. Minor complications occurred in 12 patients $(14.1 \%)$. The most common ones were fever, pain, and oliguria, in 3 patients each; pneumonia, in 1 ; and adynamic ileus, in 1. Major complications occurred in 5 patients (5.8\%): acute respiratory distress (before and after pleurodesis in 1 and 1, respectively), as well as empyema, pulmonary thromboembolism, and sepsis, in 1 patient each.

Catheter tip positioning was subpulmonary in 35 patients $(41 \%)$, anterior in $23(27 \%)$, posterolateral in $17(20 \%)$ and fissural in $10(12 \%)$. The two initial raters agreed in 79 cases (92.9\%). Disagreements involved the subpulmonary and anterior groups (3
Table 1. Characteristics of the study sample. ${ }^{a}$

\begin{tabular}{lc}
\hline \multicolumn{1}{c}{ Characteristic } & Result \\
Gender & \\
$\quad$ Female & $64(75)$ \\
$\quad$ Male & $21(25)$ \\
Age, years & $60.74 \pm 12.4$ \\
KPS index & 70 \\
Etiology & \\
$\quad$ Breast & $44(52.0)$ \\
$\quad$ Lung & $20(23.5)$ \\
$\quad$ Genitourinary & $14(16.5)$ \\
$\quad$ Gastrointestinal & $5(6.0)$ \\
$\quad$ Indefinite & $2(2.0)$ \\
Sclerosing agent & \\
Talc & $51(60)$ \\
Silver nitrate & $34(40)$ \\
Oncotic cytology & \\
Positive & $62(73)$ \\
Negative & $5(6)$ \\
Suspected & $18(21)$ \\
\hline
\end{tabular}

KPS: Karnofsky Performance Status. aValues expressed as $n(\%)$ or mean $\pm S D$, except where otherwise indicated. 'Value expressed as median.

patients each). All of those cases were solved by the third investigator, and a consensus was reached.

The median pleural volume on iCT scans was $377 \mathrm{~mL}$ (interquartile range [IQR]: 171-722 mL). There were no 
significant differences among the groups $(p=0.645)$. The median pleural volumes in the posterolateral, anterior, fissural, and subpulmonary groups were, respectively, $470 \mathrm{~mL}$ (IQR: $185-644 \mathrm{~mL}$ ), $340 \mathrm{~mL}$ (IQR: 157-1,048 mL), $296 \mathrm{~mL}$ (IQR: 92-679 mL), and $367 \mathrm{~mL}$ (IQR: 177-714 mL; Figure 2).

The median difference between the pleural volumes on CT30 and ICT scans was $33 \mathrm{~mL}$ (IQR: -225 to 257 $\mathrm{mL})$. There were no significant differences among the groups $(p=0.923)$. The median difference between those volumes in the posterolateral, anterior, fissural, and subpulmonary groups were, respectively, $73 \mathrm{~mL}$ (IQR: -217 to $219 \mathrm{~mL}$ ), $93 \mathrm{~mL}$ (IQR: -446 to 268 $\mathrm{mL}),-15 \mathrm{~mL}$ (IQR: -322.2 to 334.2 ), and $-27 \mathrm{~mL}$ (IQR: -225 to $259 \mathrm{~mL}$; Figure 3).

Pleurodesis was successful in 73 patients (85.8\%), with a similar distribution in the posterolateral, anterior, fissural, and subpulmonary groups (88.2\%, 78.3\%, $90.0 \%$, and $88.7 \%$, respectively; $p=0.676$; Figure 4 ).

As mentioned before, we used two agents to induce pleurodesis. We found no significant difference between the use of talc or silver nitrate regarding their clinical effectiveness ( $82.7 \%$ vs. $91.4 \% ; p=0.247)$. The median difference between the pleural volumes on CT30 and iCT scans was $58 \mathrm{~mL}$ (IQR: -124 to $278 \mathrm{~mL}$ ) and $81 \mathrm{~mL}$ (IQR: -402 to $245 \mathrm{~mL}$ ) using talc and silver nitrate, respectively $(p=0.08)$. We also compared the clinical effectiveness between the patients with confirmed RMPE and those with highly suspected RMPE.

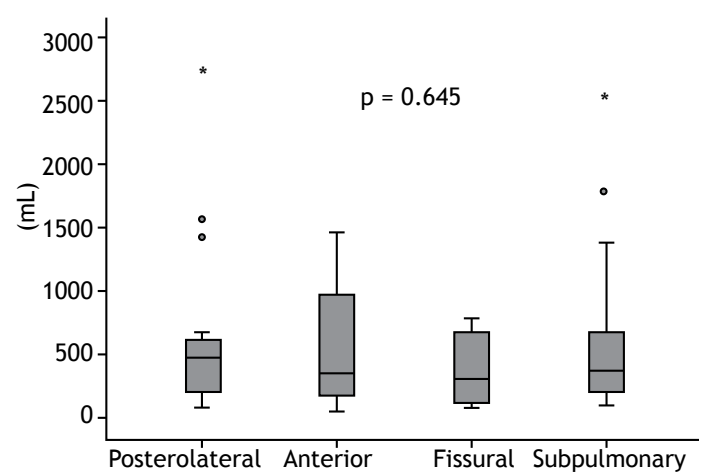

Figure 2. Initial pleural volume on CT scans.

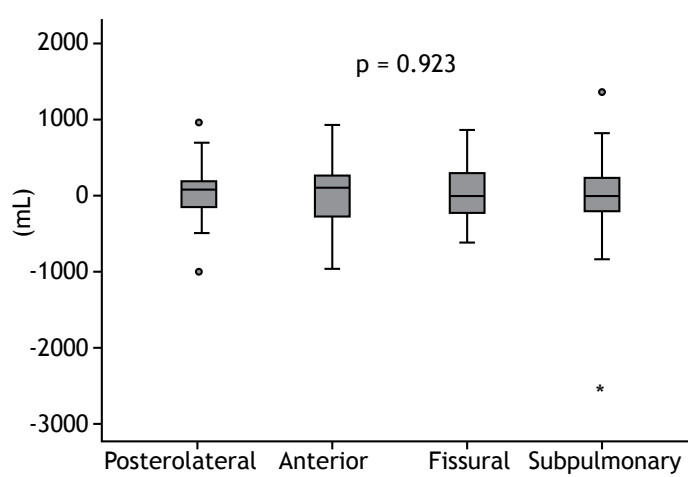

Figure 3. Difference between pleural volumes (based on final and initial CT scans).
Again, there was no significant difference $(88.8 \%$ and $78.4 \%$, respectively; $p=0.22$ ).

\section{DISCUSSION}

The results of the present study suggest that the position of the pleural catheter tip influences neither the emptying of pleural effusion nor the success of pleurodesis, either radiologically or clinically, in patients with RMPE. The pleural fluid volume measured on CT scans performed after drainage was similar among the groups representing all different intrapleural positions of the tip of the catheter. Likewise, we found no differences among the groups with regard to the accumulation of effusion 30 days after pleurodesis.

Various approaches have been used in the treatment of RMPE. These patients have poor life expectancy; thus, a less invasive method, which can be performed on an outpatient basis, should be the best option. ${ }^{(11)}$ In this scenario, bedside pleurodesis with a small-bore chest tube is a good approach. The use of ultrasonography guidance helps to decrease the complication rate due to catheter insertion. ${ }^{(1)}$ The success rate of bedside pleurodesis ranges between $81 \%$ to $96 \%$, and major complications occur in $7.5 \%$ of the cases. ${ }^{(12-15)}$ In the present study, we found similar results, since pleurodesis was successful in 73 patients $(85.8 \%)$ and major complications occurred in 5 patients (5.8\%).

To the extent of our knowledge, there is only one study that explored the correlation between the success of pleurodesis and the positioning of the chest tube tip. Ishikawa et al. ${ }^{(16)}$ conducted a prospective study in which 20 patients with lung cancer and RMPE underwent pleural drainage with a new curved chest tube developed by them. The new chest tube had a diameter of $18 \mathrm{Fr}$ and smooth curved distal parts in order to allow a better positioning of its tip into the pleural cavity. To evaluate the position of the tip, frontal and lateral chest $\mathrm{X}$-rays were taken after the insertion and before the removal of the tube. The position was classified as paravertebral gutter in posterobasal position (15 patients, 75\%), posterior and superior position of the pleural space (4 patients, $20 \%$ ), or pleural space other than the two previous positions ( 1 patient, $5 \%$ ). A drainage efficacy of more than $90 \%$ on X-rays was achieved in $86.7 \%$ of the patients in the paravertebral group; however, only $25 \%$ of those

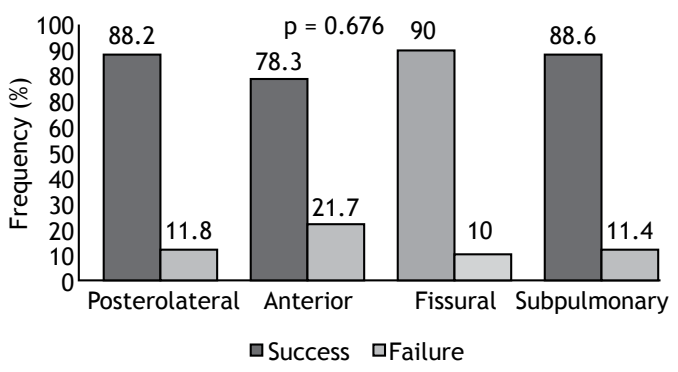

Figure 4. Pleurodesis success according to the positioning of the tip of the catheter. 
in the posterior-superior group had the same efficacy $(p=0.024)$. Bedside pleurodesis was successful in all of those cases; nevertheless, the patients who were not in the paravertebral group achieved no full radiographic resolution within a four-week follow-up. Unfortunately, we have found no other studies addressing that new device or the relevance of the intrapleural position of the chest tube.

On the basis of the findings of Ishikawa et al., ${ }^{(16)}$ we sought to direct the tip of the chest tube superiorly and posteriorly. Nonetheless, small-bore catheters are much more flexible, making it difficult to predict where they will eventually lie in the pleural space. This fact is confirmed by the finding that the catheter was positioned posterolaterally in only $20 \%$ of our patients, in spite of our effort to push it in such a direction. Probably, after pleural effusion drainage and lung expansion, the tip assumes different random positions. However this discussion now seems less relevant because we found, in the present study, that the position of the tip had no influence on clinical or radiological outcomes.

Our broad inclusion and exclusion criteria allowed a good generalizability of our results, which we believe might be applicable for patients with RMPE treated at other tertiary care facilities. Moreover, the pleural catheter that we used is one of the most popular catheters worldwide. One threat to the generalizability of the present study is the fact that more than $50 \%$ of the patients had breast cancer. In addition, in relation to the initial lung expansion, since we only included patients with RMPE, we cannot say that our results can be generalized to other types of pleural effusion.

The major limitation of our study is the fact that it is a secondary analysis of data collected for a different purpose. Moreover, the number of cases with clinical failure of pleurodesis was small ( 9 patients), hindering a powerful statistical analysis of this outcome. We also found a very wide distribution of values of pleural volumes measured on $\mathrm{CT}$, reflecting the heterogeneity of our study population (various primary cancers at various stages of treatment) and broad inclusion criteria. However, the main strength of the study is the very precise method we used in order to measure lung expansion after drainage and to estimate pleural fluid reaccumulation. The CT scans allowed us to measure pleural volumes with certainty, making our conclusions stronger.

In conclusion, the present study demonstrated that, regardless of the ultrasound-guided positioning of the small-bore pleural catheter, pleural drainage and pleurodesis were efficient in our sample of patients. Therefore, the position of the tip of the pleural catheter seems to be of low relevance and should not hinder the instillation of a sclerosing agent or pleurodesis.

\section{ACKNOWLEDGMENTS}

We would like to thank the University of São Paulo Medical School Graduate Program in Thoracic and Cardiovascular Surgery.

\section{REFERENCES}

1. Light RW. Pleural controversy: Optimal chest tube size for drainage Respirology. 2011;16(2):244-8. https://doi.org/10.1111/j.1440 1843.2010.01913.x

2. Lombardi G, Zustovich F, Nicoletto MO, Donach M, Artioli G Pastorelli D. Diagnosis and treatment of malignant pleural effusion: a systematic literature review and new approaches. Am J Clin Oncol. 2010;33(4):420-3. https://doi.org/10.1097/COC.0b013e3181aacbbf

3. Owen S, Gould D. Underwater seal chest drains: the patient's experience. J Clin Nurs. 1997:6(3):215-25. https://doi. org/10.1111/j.1365-2702.1997.tb00307.x

4. Havelock T, Teoh R, Laws D, Gleeson F; BTS Pleural Disease Guideline Group. Pleural procedures and thoracic ultrasound: British Thoracic Society Pleural Disease Guideline 2010. Thorax. 2010;65 Suppl 2:ii61-76. https://doi.org/10.1136/thx.2010.137026

5. Parulekar W, Di Primio G, Matzinger F, Dennie C, Bociek G. Use of small-bore vs large-bore chest tubes for treatment of malignant pleural effusions. Chest. 2001;120(1):19-25. https://doi.org/10.1378/ chest.120.1.19

6. Clementsen P, Evald T, Grode G, Hansen M, Krag Jacobsen G, Faurschou P. Treatment of malignant pleural effusion: pleurodesis using a small percutaneous catheter. A prospective randomized study. Respir Med. 1998;92(3):593-6. https://doi.org/10.1016/S0954 6111(98)90315-8

7. Caglayan B, Torun E, Turan D, Fidan A, Gemici C, Sarac G, et al. Efficacy of iodopovidone pleurodesis and comparison of smallbore catheter versus large-bore chest tube. Ann Surg Oncol 2008;15(9):2594-9. https://doi.org/10.1245/s10434-008-0004-1

8. Lechtzin N. How to Do Tube Thoracostomy [monograph on the Internet]. Kenilworth, NJ: Merck Manual Professional Version; 2016 [cited 2016 Aug 1]. Available from: https://www.merckmanuals. com/professional/pulmonary-disorders/diagnostic-and-therapeuticpulmonary-procedures/how-to-do-tube-thoracostomy
9. Kwiatt M, Tarbox A, Seamon MJ, Swaroop M, Cipolla J, Allen C, et al Thoracostomy tubes: A comprehensive review of complications and related topics. Int J Crit IIIn Inj Sci. 2014;4(2):143-55.

10. U.S. Department of Health and Human Services. National Institutes of Health. National Cancer Institute. Common Terminology Criteria for Adverse Events (CTCAE). Version 4.0. Washington: U.S Department of Health and Human Services; 2010.

11. Roberts ME, Neville E, Berrisford RG, Antunes G, Ali NJ; BTS Pleural Disease Guideline Group. Management of a malignant pleural effusion: British Thoracic Society Pleural Disease Guideline 2010. Thorax. 2010;65 Suppl 2:ii32-40. https://doi.org/10.1136/ thx.2010.136994

12. Terra RM, Kim SY, Pego-Fernandes PM, Teixeira LR, Vargas FS, Jatene FB. Is silver nitrate pleurodesis for patients with malignant pleural effusion feasible and safe when performed in an outpatient setting? Ann Surg Oncol. 2011;18(4):1145-50. https://doi. org/10.1245/s10434-010-1447-8

13. Genofre EH, Vargas FS, Acencio MM, Antonangelo L, Teixeira LR Marchi E. Talc pleurodesis: evidence of systemic inflammatory response to small size talc particles. Respir Med. 2009;103(1):91-7. https://doi.org/10.1016/j.rmed.2008.07.021

14. Huggins JT, Doelken $P$, Sahn SA. Intrapleural therapy. Respirology 2011;16(6):891-9. https://doi.org/10.1111/j.1440-1843.2011.02011.x

15. de Campos JR, Vargas FS, de Campos Werebe E, Cardoso P Teixeira LR, Jatene FB, et al. Thoracoscopy talc poudrage: a 15year experience. Chest. 2001;119(3):801-6. https://doi.org/10.1378/ chest.119.3.801

16. Ishikawa H, Satoh H, Yamashita YT, Kamma H, Naito T, Ohtsuka M et al. Curved chest tube for drainage of malignant pleural effusion. Respir Med. 1998;92(4):633-7. https://doi.org/10.1016/S0954 6111(98)90509-1 